\section{CPR quality reduced due to physical fatigue after a water rescue in a swimming pool}

\author{
ROBERTO BARCALA-FURELOS - CRISTIAN ABELAIRAS-GOMEZ • \\ ANA CATARINA QUEIROGA • JOSÉ LUIS GARCÍA-SOIDÁN
}

\author{
ANA CATARINA QUEIROGA $(\square) \bullet$ \\ ROBERTO BARCALA-FURELOS • \\ CRISTIAN ABELAIRAS-GOMEZ • \\ JOSÉ LUIS GARCÍA-SOIDÁN \\ Faculty of Education and Sport Sciences \\ University of Vigo \\ Campus a Xunqueira \\ 36005 Pontevedra, Spain \\ Phone: 0034986802054 \\ E-mail: acqueiroga@me.com
}

\begin{abstract}
Objective. This study aimed to analyse the influence of physical fatigue, resulting from a simulated aquatic rescue, at a swimming pool, on the quality of cardiopulmonary resuscitation (CPR) delivered by the rescuer.

Design, setting and participants. An intragroup design with 27 lifeguards was used in this study. The quality of CPR delivery was evaluated for two minutes for all subjects while they were at rest (test 1), as well as after a simulated aquatic rescue at a swimming pool (test 2). A Resusci Anne ${ }^{\circledR}$ SkillReporter ${ }^{\text {TM }}$ (Laerdal Medical Limited, Norway) manikin was used to retrieve reports on CPR delivery, compliant with the most recent international guidelines $(30: 2$, chest compression: ventilation ratio).

Results. Rescue-related physical fatigue had a significant influence on the total number of chest compressions as well as on the ratio of correct chest compressions. Physical fatigue triggered by a swimming pool water rescue negatively influenced CPR delivery quality. These results show that the detrimental effects of physical fatigue on CPR delivery remain important, even in a swimming pool environment.

Conclusions. Training programs should reflect this finding, and focus on enabling lifeguards to deliver proper CPR, even while exhausted and for long periods of time.
\end{abstract}

Key words: emergency medicine, drowning, resuscitation

\section{Introduction}

Unintentional drowning is a leading cause of death worldwide. It is ranked eighth as the cause of death for individuals under 20 years of age worldwide, (1) and it is the second cause of accidental death among young people in Europe. (2) In Spain, a country with around 2,700 beaches and 400,000 swimming pools, in 2010 there were 2,067 accidental deaths reported as being caused by drowning, submersion and suffocation. (3) Swimming and recreating while in the water was reported as the most common activity undertaken immediately prior to drowning by men aged 18-34 years in Australia. (4) Additionally, international reports have shown that swimming pools are the main aquatic environment where children and adolescents aged 0 - 19 drown. (5)

Given that the use of aquatic environments for leisure and health-related activities is becoming increasingly popular, (6) the presence of lifeguards in swimming areas, as recommended by the $\mathrm{WHO}$, is of utmost importance in order to prevent and reduce the number of deaths by drowning. (7)

The rescue of a drowned person is one of the most delicate interventions a lifeguard may need to perform, since the respiratory failure caused by the drowning event will most certainly trigger a cardiac arrest. Deaths by drowning in pools with lifeguards are not common, but do occur. (8) In the event of a cardiac arrest, both the European Resus- citation Council and the American Heart Association recommend cardiopulmonary resuscitation (CPR) to be performed as early as possible, $(4,8,9)$ but also emphasize that the quality of the reanimation must not be disregarded. Furthermore, the European Resuscitation Council Guidelines for Resuscitation (ERCGR) 2010 recommend that the rescuer should be relieved after two minutes of reanimation due to the onset of fatigue in that rescuer. (10) The decrease in CPR quality due to physical fatigue has been studied for many years, but most scientific studies that address the subject focus on "at-the-hospital" (11) or "pre-hospital" CPR (12) performed by medical personnel, in scenarios where the rescuers start the reanimation without having previously become fatigued. Neverthe- 
less, for other emergency teams, such as fire fighters or lifeguards, it is likely that the rescuer will already be wornout when starting the CPR procedure. Studies such as those by Claesson et al. (13) and Barcala-Furelos et al. (14) evidenced the negative effects of fatigue on the quality of CPR delivery after beach water rescues. However, to the best of our knowledge, no similar study addressing this issue after a swimming pool rescue has been conducted. Given that anecdotal evidence points to the fact that swimming pool rescues involve less physical effort than those performed at a beach, it is important to evaluate whether the findings from previous studies hold true in a swimming pool environment.

Therefore, the aim of this study was to analyse the influence of physical fatigue, after a rescue in a swimming pool, on the effectiveness of the cardiopulmonary resuscitation delivered, according to the 2010 European Resuscitation Council Guidelines for Resuscitation.

\section{Methods}

Study design

A quasi-experimental design was used to evaluate the performance of CPR provided by lifeguards while at rest and exhausted after a rescue. Initially, several anthropometric and demographic variables were gathered for each subject: gender, height, age, weight and body mass index (BMI).

The first phase of this project consisted of an analysis of CPR performance by a group of lifeguards after a rescue at a surf beach, compared to the CPR performance of the same subjects while at rest. The results and further detailed information of this phase of the project have been reported elsewhere. (14)

The tests conducted in this study aimed to evaluate the effect of physical fatigue on CPR performance after a water rescue in a swimming pool. Participants had to perform two tests. The first test conducted (test 1) consisted of providing CPR (at rest) according to ERCGR 2010 -i.e., with a compression: ventilation ratio of 30:2, for two minutes. All participants performed test 1 in the laboratories of

a)

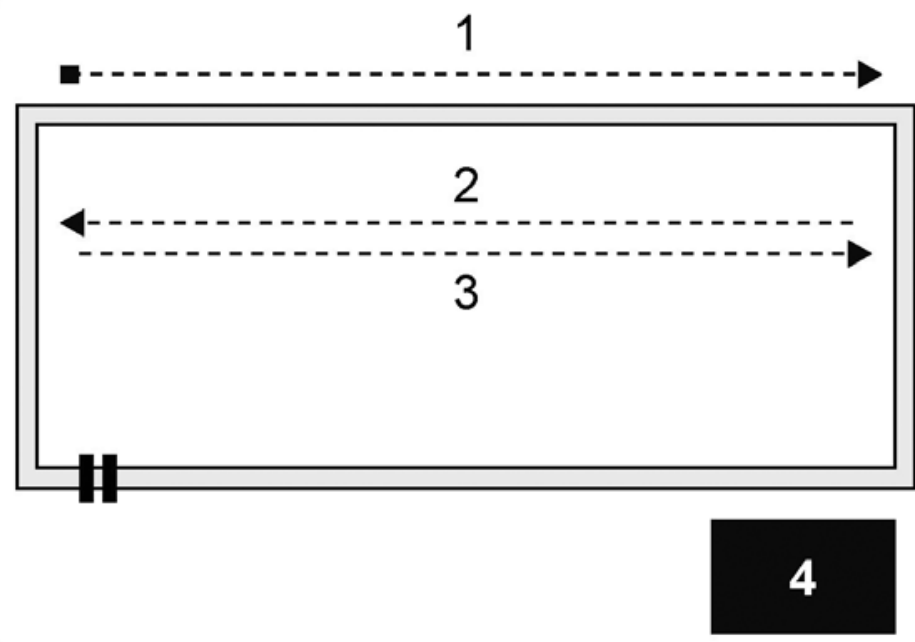

b)
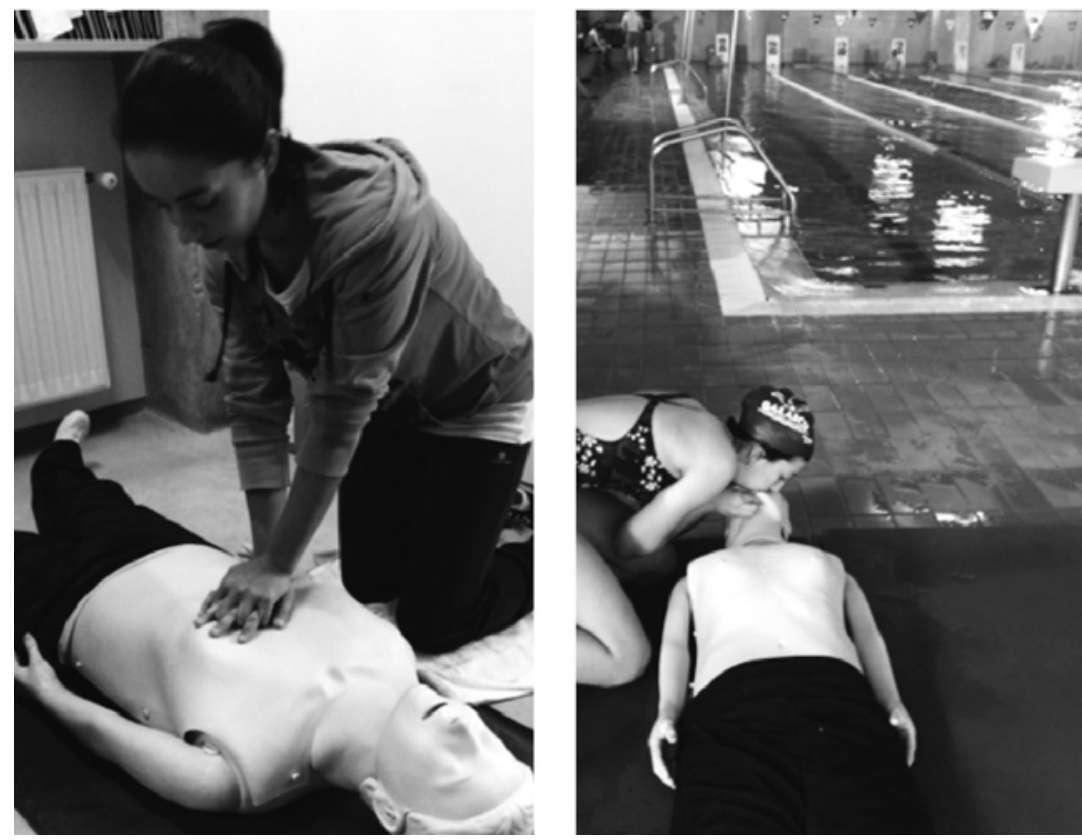

Figure 1. Tests Schematic.

A Overview of test 2 (cardiopulmonary resuscitation (CPR) after rescue): 1 - $25 \mathrm{~m}$ run; 2 - $25 \mathrm{~m}$ swim; 3 -towing the victim $25 \mathrm{~m}$ to the other end of the pool; 4 - conducting CPR for 2 min after rescue. $B$ Images of places where CPR was conducted in test 1 and 2, left and right, respectively.

the Faculty of Education and Sport Sciences, University of Vigo, Spain. The same group of participants performed a second test (test 2), consisting of: a $25 \mathrm{~m}$ run from one side of the pool to the other, followed by a $25 \mathrm{~m}$ swim, and towing the victim $25 \mathrm{~m}$ to the other end of the pool (figure 1). Breaststroke kick was used both for swimming and towing. The total rescue time was recorded. Immediately after towing the victim to the end of the pool, the rescuer provided outof-water CPR for 2 min (exhausted) to a manikin equipped with a performance recorder. Participants were allowed to rest 1 day between tests 1 and 2 . The latter was conducted at the municipal pool of Campolongo, a $25 \mathrm{~m}$ indoor pool, in the city of Pontevedra, Spain. A 24 year old swimmer, $176 \mathrm{~cm}$ tall and weighing $75 \mathrm{~kg}$, played the role of an unconscious victim on the surface of 
CPR PERFORMANCE MEASUREMENTS

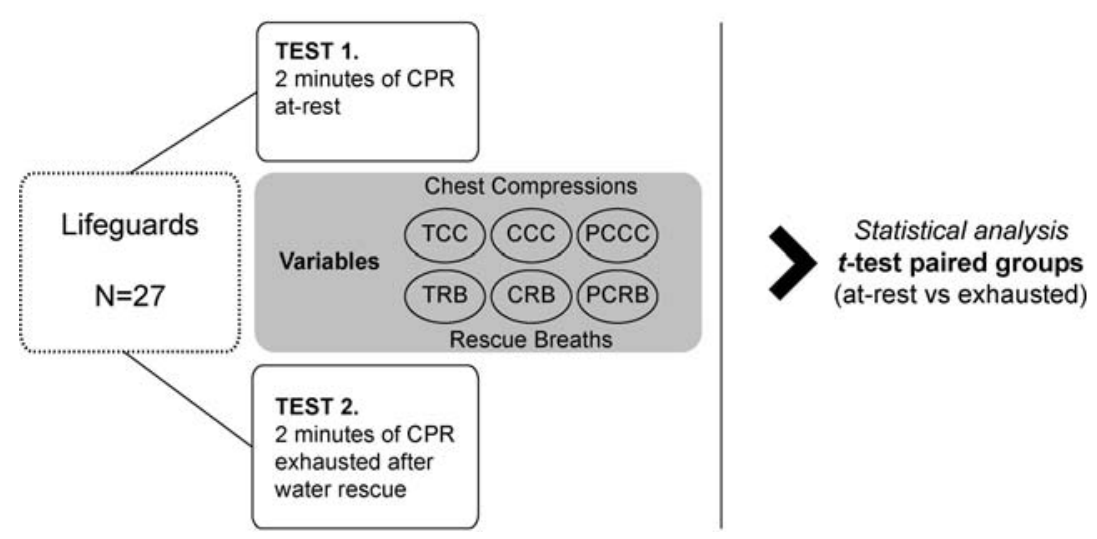

Figure 2. Study Design.

CCC, Correct chest compression; CRB, Correct rescue breath; PCCC, Percentage of correct chest compressions; PCRB, Percentage of correct rescue breaths; TCC, Total chest compressions; TRB, Total rescue breaths.

the water. The rescuers towed the victim by the neck using a breaststroke kick without any auxiliary rescue equipment. The lifeguards were explicitly advised to perform the test as if it was a real water rescue and didn't perform in-water ventilations, believed to affect the physical intensity of the rescue. A summary of the study design is presented in figure 2 .

Participants

The 27 participants in the study were Galician lifeguards. The sampling was non probabilistic. The initial sample size was 30 lifeguards; however, 3 subjects were removed from the study because they were not able to complete the entire protocol. All subjects had been trained at the University of Vigo according to ERCGR 2010 recommendations. Each participant signed an informed consent form, after receiving verbal explanations of the objectives and methodology of the trials. Before the beginning of the study, ethics approval was obtained from the Illustrious Official School of Graduates in Physical Education and Sport Sciences of Galicia Ethics Committee according to the ethical principles of the Helsinki Convention (approval number C-145/13).

Research Instruments

A Resusci Anne ${ }^{\circledR}$ SkillReporter ${ }^{\text {TM }}$ (Laerdal Medical Limited, Norway) manikin was used to retrieve reports on CPR delivery compliance. This model gives immediate feedback both on the quality of chest compressions and ventilations but the rescuers couldn't see the feedback provided by the mannequin while performing the tests. To study the quality of chest compressions, the manikin was calibrated to measure several parameters such as the depth, frequency, position of the hands and chest reexpansion. Regarding the ventilations, the equipment measured the respiratory tidal volume and the flow rate per minute. At no time could the rescuers see the feedback given by the manikin. Based on ERCGR 2010 recommendations, the rescuers performed $\mathrm{CPR}$ at a compression: ventilation ratio of 30:2. Correct compressions were recorded on the manikin as: $5-6 \mathrm{~cm}$ in depth, good hand-position and chest re-expansion, and correct ventilations as $500-600 \mathrm{ml}$ in volume. Variables considered for the evaluation of the impact of physical fatigue on CPR performance are depicted in figure 1.

Data collection and Statistical Analysis Information on gender, height, weight, and BMI was collected, total rescue time was registered and the number of total and correct chest compressions and rescue breaths (at rest and exhausted), were recorded by the manikin recording system and manually uploaded to the statistical software used for data analysis.
Statistical analysis was performed using SPSS for Windows, version 20 (SPSS Inc., IBM, USA). Continuous variables are reported using measures of central tendency (mean) and dispersion (standard error) (Mean \pm SE). The sample was tested for normality using the Shapiro-Wilks normality test. A paired t-test (student distribution) was used to compare total and correct chest compressions and ventilations, within each minute of the study, while at rest and exhausted, separately. Repeated measures ANOVA was used in order to compare the effect of the test (at rest vs. exhausted), the minute of CPR (minute 1 vs. minute 2) and the interaction between these two factors (test $x$ minute). A $p<0.05$ was considered significant.

\section{Results}

\section{Demographic data}

Of the 30 lifeguards selected to participate in the study, a sample of 27 completed the protocol successfully. Of those, 23 were males and 4 females, with an average age of 21 ( $\mathrm{SE}=0.3$ ). Table 1 shows the anthropometric data of the study sample. The age range of the participants varied between 19 and 24 and all participants had enrolled in a CPR training programs in the last 3 months prior to the study. Due to the low sample size and small number of females participating in this preliminary study, analysis of the effect of gender and other demographics on CPR performance was not conducted.

Rescue time before CPR

In test 2, rescuers had to run $25 \mathrm{~m}$, swim $25 \mathrm{~m}$ to approach the victim, tow the victim for $25 \mathrm{~m}$ to the side of the pool, and then perform CPR on a manikin. The time taken to perform the rescue, before starting CPR manoeuvres, averaged $77.6 \mathrm{~s} \pm 1.2$.

\section{CPR Performance}

Table 1 shows the average and standard error of data from the CPR performed for 2 minutes in the laboratory and after the water rescue. Table 2 shows detailed data regarding chest compressions and rescue breaths per minute of CPR delivery for test 1 and 2 (at rest and 
exhausted, respectively). A high percentage of correct compressions after 2 min were achieved while the lifeguards were at rest, $86.3 \% \pm 3.8$, but the same did not happen for the ventilations performed while participants were exhausted, where merely $45.4 \% \pm 5.6$ of them were performed correctly. It is possible to conclude that after performing CPR on the manikin for $2 \mathrm{~min}$, the physical fatigue resulting from the rescue had a significant influence both on the Total number of Chest Compressions (TCC) $137 \pm 2.0$ at rest compared to $151 \pm 2.1$ while exhausted $(p<0.001)$, and on the correlated Percentage of Correct Chest Compressions (PCCC) $86.3 \% \pm 3.8$ at rest compared to $69.6 \pm 6.3$ while exhausted $(p<0.029)$ (table 2$)$. When looking at the "time" factor (1 min vs. 2 min), using the Repeated Measures ANOVA, differences were significant in TCC and total rescue breaths (TRB). In the interaction of both factors (test and time), significant differences were found in TCC, PCC, and TRB (table 2). When analysing each minute separately in both tests 1 and 2 (at rest vs. exhausted), it is possible to identify further differences in the onset of fatigue. During the first minute of CPR, fatigue had a significant influence, both increasing the number of TCC and reducing the PCCC. Conversely, during the second minute fatigue had no significant effect on the quality of chest compressions.

\section{Discussion}

Data from this study strongly suggest that physical fatigue resulting from a water rescue in a swimming pool negatively influences the quality of cardiopulmonary resuscitation.

Before performing test 2, the rescuers performed CPR for two minutes while at rest (test 1). This first test had two main objectives: first, the data at rest was necessary as a control measurement to assess the effects of fatigue on CPR quality; secondly, test 1 was used to assess the skills of the first set of 30 participants in performing CPR correctly.

During the two minutes of CPR at rest, rescuers delivered over $80 \%$ correct compressions (firstminute: $88.8 \% \pm 3.2$;

Table 1. Descriptive statistics of data collection.

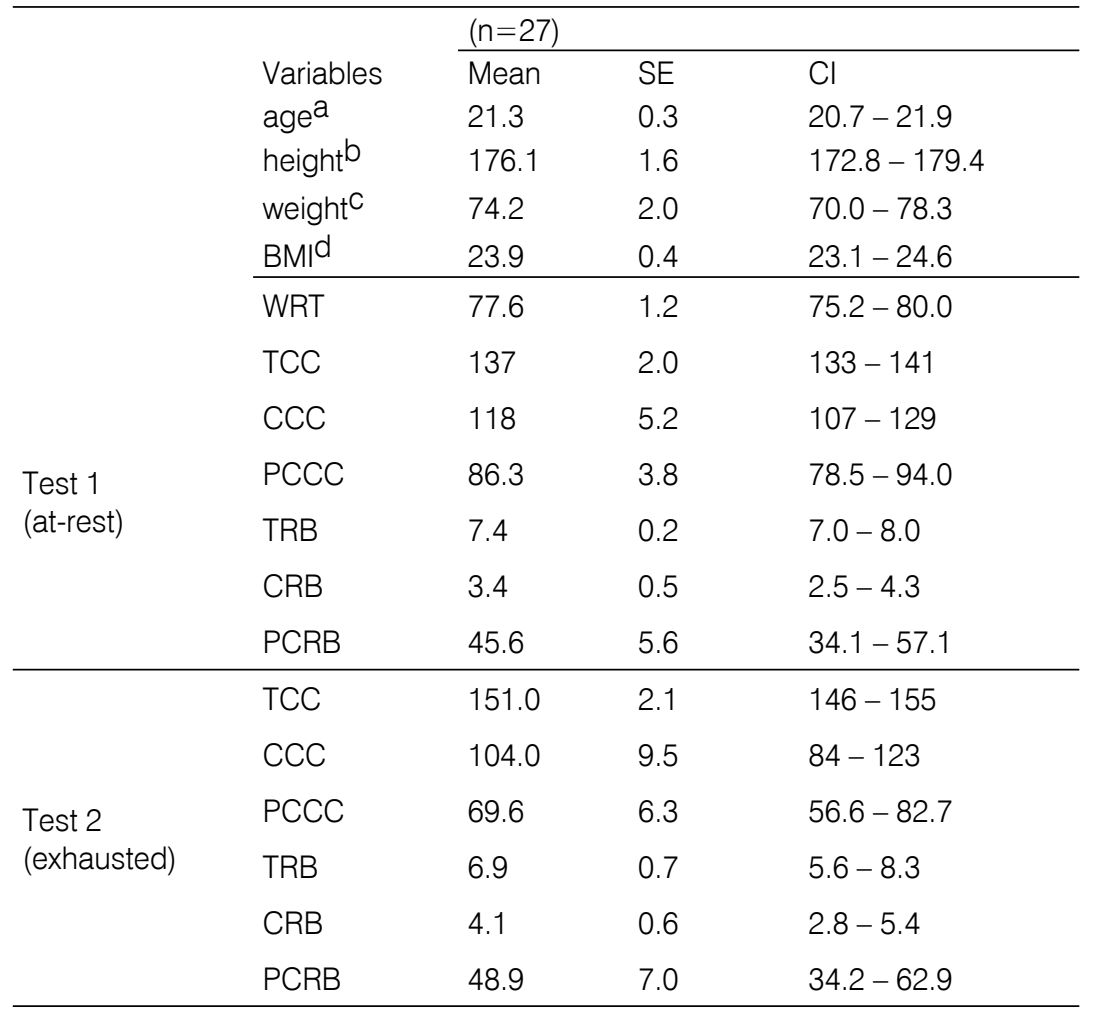

a: Age in years; b: Height in $\mathrm{cm}$; ${ }^{\text {: }}$ Weight in $\mathrm{kg}$; $\mathrm{d}$ : Body mass index, $\mathrm{kg} \cdot \mathrm{m}^{-2}$;

CCC, Correct chest compression; $\mathrm{Cl}$, Confidence Interval; CRB, Correct rescue breaths; PCCC, Percentage of correct chest compressions; PCRB, Percentage of correct rescue breaths; SE, Standard Error; TCC, Total chest compressions; TRB, Total rescue breaths; WRT, Water rescue time.

second minute: $84.0 \% \pm 5.2$ ) (table 2). It has been referenced that chest-compression effectiveness equal or superior to $70 \%$ is considered an indicator of good quality CPR. (15) Therefore, the 27 lifeguards selected to participate in the study were considered proficient in delivering CPR chest-compressions. Regarding ventilations, not only did the rescuers provide slightly fewer than the recommended number, (10) but they also did it poorly with a ratio of effectiveness below $50 \%$ (table 1 ).

The paramount importance of ventilations for treating a drowning victim has been advocated by experts worldwide. $(11,16-18)$ In fact, a study by Szpilman and Soares (17) concluded that performing in-water ventilations increases the chances of survival of the victim; and later, in a pilot evaluation, Perkins (16) demonstrated the possibility of proper ventilation in the water, with flotation material, and previous training. Despite the scientific evidence supporting the importance of ventilations, some studies reported that lifeguards perform ventilations poorly, $(10,19)$ pointing to a potential gap in the training programs that needs further investigation.

In the present study, the rescuers were told not to perform in-water ventilations to avoid the decrease of intensity in the rescue. To evaluate the effect of fatigue on the quality of CPR the participants performed a simulated water rescue similar to the one they have to perform to achieve the Aquatic Lifeguard Certificate to be qualified to work at aquatic facilities in Spain. The test encompasses running for $25 \mathrm{~m}$, swimming for 25 $\mathrm{m}$ and towing the victim for another 25 min in less than $90 \mathrm{~s}$. Since all participants performed the rescue in less than 
Table 2. ANOVA Repeated Measures for variables associated with differences among at rest and exhausted lifeguards and time.

\begin{tabular}{|c|c|c|c|c|c|c|c|c|c|c|}
\hline \multirow[b]{2}{*}{ Variables } & & \multicolumn{3}{|c|}{ CPR at rest } & \multicolumn{3}{|c|}{ CPR exhausted } & \multicolumn{3}{|l|}{ ANOVA } \\
\hline & & Mean & SE & $\mathrm{Cl}$ & Mean & SE & $\mathrm{Cl}$ & $\begin{array}{l}\text { Test }^{A} \\
\text { F-p }\end{array}$ & $\begin{array}{l}\operatorname{Min}^{B} \\
\text { F-p }\end{array}$ & $\begin{array}{l}\text { AxB } \\
\text { F-p }\end{array}$ \\
\hline \multirow{2}{*}{ TCC } & Min1 & 69.0 & 0.9 & $67-71$ & 77.0 & 1.5 & $74-80$ & 22.337 & 5.877 & 4.658 \\
\hline & Min2 & 69.0 & 1.1 & $66-71$ & 74.0 & 1.0 & $72-76$ & $<0.001$ & 0.023 & 0.040 \\
\hline \multirow{2}{*}{ CCC } & Min1 & 61.0 & 2.2 & $56-65$ & 50.0 & 5.5 & $37-61$ & 1.500 & 0.002 & 2.410 \\
\hline & Min2 & 57.0 & 3.6 & $50-64$ & 54.0 & 4.8 & $44-64$ & 0.232 & 0.968 & 0.133 \\
\hline \multirow{2}{*}{ PCCC } & Min1 & 88.8 & 3.2 & $82.3-95.4$ & 64.9 & 6.9 & $50.7-79.1$ & 5.363 & 0.411 & 5.023 \\
\hline & Min2 & 84.0 & 5.2 & $73.4-94.7$ & 74.4 & 6.8 & $60.4-88.4$ & 0.029 & 0.527 & 0.034 \\
\hline \multirow{2}{*}{ TRB } & Min1 & 3.8 & 0.1 & $3.6-4.0$ & 3.0 & 0.3 & $2.4-3.7$ & 0.551 & 4.630 & 14.478 \\
\hline & Min2 & 3.7 & 0.2 & $3.3-4.0$ & 3.9 & 0.4 & $3.1-4.7$ & 0.465 & 0.041 & 0.001 \\
\hline \multirow{2}{*}{ CRB } & Min1 & 1.7 & 0.3 & $1.2-2.7$ & 1.9 & 0.3 & $1.3-2.6$ & 1.390 & 0.243 & 1.711 \\
\hline & Min2 & 1.7 & 0.3 & $1.1-2.3$ & 2.2 & 0.4 & $1.5-3.0$ & 0.249 & 0.626 & 0.202 \\
\hline \multirow{2}{*}{ PCRB } & Min1 & 45.7 & 6.4 & $32.6-58.8$ & 50.3 & 7.4 & $35.1-65.6$ & 0.304 & 0.010 & 0.020 \\
\hline & Min2 & 46.9 & 7.8 & $30.9-62.9$ & 50.2 & 7.7 & $34.2-66.1$ & 0.586 & 0.922 & 0.888 \\
\hline
\end{tabular}

CCC, Correct chest compression; CRB, Correct rescue breaths; PCCC, Percentage of correct chest compressions; PCRB, Percentage of correct rescue breaths; TCC, Total chest compressions; TRB, Total rescue breaths.

A: Test factor (rested vs. exhausted); B: Minute factor (minute 1 vs. minute 2).

$90 \mathrm{~s}$, with an average time of $77.6 \pm 1.2$ $\mathrm{s}$, we can consider them as suitable for the tests performed in the study. According to the ERCGR 2010, (12) CPR alone generates fatigue in the rescuer, and therefore, rest is recommended every two minutes. The importance of fatigue generated by CPR has driven several research projects for the last years, with results supporting the ERCGR 2010 recommendations. (14,20-23) Few have, however, claimed that lifeguards are capable of maintaining the quality of CPR for extended periods of time. $(22,24)$ Nevertheless, since Emergency Medical Services take about 5-8 min to get to the place of incident, $(12,25,26)$ in a best case scenario, and taking as long as $20 \mathrm{~min}$, or more, depending on the country and or region where it is needed, it is possible that the lifeguard might be forced to perform CPR for a prolonged period of time. Thus, CPR training should focus on the fact that rescuers ought to be able to maintain the quality of CPR for periods longer than two minutes.

Our results suggest that lifeguards are able to maintain high quality compressions for two minutes, except when they perform CPR after a rescue. The total number of compressions increases after performing a rescue compared to the number delivered at rest, which is in accordance with other authors. $(13,14)$ Despite the increase in the total number of chest compressions provided after a rescue, the number of correct compressions decreases compared to at rest CPR, from $118 \pm 5.2$ to $104 \pm 9.5$, respectively, even though that decrease is not statistically significant $(p=0.230)$. Due to the parallel increase of total compressions and decrease in correct compressions, the effectiveness of CPR performed after the water rescue was significantly inferior, $86.3 \% \pm 3.8$ at rest compared to $69.6 \% \pm 6.3$ while exhausted $(p=0.030)$. Simultaneously, the percentage of correct compressions decreases significantly with the interaction of test and minute $(p=0.034)$. Even though the same decrease was recorded for the second minute of CPR delivery, in the latter, the difference is not statistically significant $(p=0.239)$. There is a severe decline in the quality of CPR during the first minute, which is slightly recovered in the latter while the rescuer is exhausted. Even so, the best performance while exhausted is still $10 \%$ worse than the worse performance at rest.

Nowadays, new technology is availa- ble to provide high quality chest compressions automatically, (27) such as piston chest compression, LUCAS, vest CPR, and Autopulse - load distributing band CPR. So far, few studies have been conducted in which the increased quality of compressions performed by those automatic compression devices was demonstrated $(28,29)$ for CPR conducted in a "wet" environment. Improving the quality of CPR is an important predictor of the outcome from cardiac arrest. So, the development of CPR mechanical devices that effectively work in "wet" environments can provide a good alternative to manual CPR of drowning victims, which is highly impacted by physical fatigue.

As far as ventilations are concerned, there were no significant differences between the CPR performed at rest and CPR performed after a rescue. Nevertheless, in this study the lifeguards performing CPR at rest did not reach high percentages of correct ventilations, as was the case in the study of Claesson et al. (13) which may explain the absence of a significant difference. Our study indicates that the quality of ventilations delivered by lifeguards was poor, as described by other researches. $(19,30)$ Due to the importance of quality ventila- 
tions provided during CPR for a successful outcome of the CPR performed on a drowning victim, further studies are urged to better elucidate the reasons affecting the ventilation quality in exhausted and at rest lifeguards comparing different techniques and equipment available to provide rescue breaths.

The present study has some limitations including the small share of women in the sample not allowing a genderbased comparison. Additionally, the simulation of a water rescue is not exactly the same as a real life water rescue followed by manual CPR since the emotional factors such as the level of motivation and anxiety of a lifeguard may also affect performance and can never be exactly reproduced. Finally, a manikin may offer greater or lesser resistance than a real casualty and compressions given in cycles alternating with rescue breaths might be less accurate than continuous compressions. In brief, physical fatigue after a simulated rescue in a swimming pool had a negative influence on the quality of CPR performance. The authors recommend that CPR training programs for future water safety professionals should be adjusted and conducted to enable them to learn how to perform CPR while physically exhausted and during prolonged periods of time.

Future lines of investigation should evaluate the CPR performed in a drowning victim by different emergency services professionals, with larger samples and comparing the CPR conducted both by men and women. Besides assessing the performance of chest compressions under different scenarios, special attention needs to be paid to ventilation performance due to the noticeable importance of good ventilations during $\mathrm{CPR}$, particularly in drowning victims, already pointed out as critical by several other researchers. $(11,16-19,30)$

\section{ACKNOWLEDGEMENTS}

We wish to thank all the lifeguards who made this study possible through their collaboration.

\section{REFERENCES}

1. Towner E, Scott I. Child Injuries in Context. In: Peden M, Oyegbite K, Ozanne-Smith J, Hyder AA, Branche C, Rahman AF, et al. editors. World Report on Child Injury Prevention. World Health Organization; 2008. p. 1-30.

2. MacKay M, Vincenten J. Child safety report card 2009: Europe summary for 24 countries. Amsterdam: European Child Safety Alliance, Eurosafe; 2009.

3. National Institute of Statistics. Accidental deaths caused by drowning, submersion and suffocation. Available from: URL: http://www.ine. es/jaxi/tabla.do?type = pcaxis\&path $=/$ t15/p417/a2010/10/\&file=01001.px

4. Royal Life Saving Australia. Australia National Drowning Report 2013. Royal Life Saving Society; 2013

5. Queiroga AC, Peden A. A 10 year analysis of drowning in children and adolescents aged 5-19 years in Australia: The Forgotten 50\%. Royal Life Saving Australia; 2013.

6. Petrass LA, Blitvich JD, Finch CF. Observations of caregiver supervision of children at beaches: identification of factors associated with high supervision. Inj Prev 2011;17(4):244-9.

7. Taneja G, van Beeck E, Brenner RA. Drowning. In Peden M, Oyegbite K, Ozanne-Smith J, Hyder AA, Branche C, Rahman AF, et al. editors. World Report on Child Injury Prevention. World Health Organization. 2008. p. 59-78.

8. Pelletier AR, Gilchrist J. Fatalities in swimming pools with lifeguards: USA, 2000-2008. Inj Prev 2011;17(4):250-3.

9. Travers AH, Rea TD, Bobrow BJ, Edelson DP, Berg RA, Sayre MR, et al. Part 4: CPR Overview. 2010 American Heart Association Guidelines for Cardiopulmonary Resuscitation and Emergency Cardiovascular Care. Circulation 2010;122:S676-84.

10. United States Lifeguard Coalition. United States Lifeguard Standards: An Evidence-Based Review and Report by the United States Lifeguard Standards Coalition. Int J Aquat Res Educ 2011;5(1):61-129.

11. Soar J, Perkins GD, Abbas G, Alfonzo A, Barelli A, Bierens JJLM, et al. European Resuscitation Council Guidelines for Resuscitation 2010 Section 8. Cardiac arrest in special circumstances: Electrolyte abnormalities, poisoning, drowning, accidental hypothermia, hyperthermia, asthma, anaphylaxis, cardiac surgery, trauma, pregnancy, electrocution. Resuscitation 2010;81(10):1400-33.

12. Koster RW, Baubin MA, Bossaert LL, Caballero A, Cassan P, Castrén M, et al. European Resuscitation Council Guidelines for Resuscitation 2010 Section 2. Adult basic life support and use of automated external defibrillators. Resuscitation 2010;81(10):1277-92.

13. Claesson A, Karlsson T, Thorén A-B, Herlitz J. Delay and performance of cardiopulmonary resuscitation in surf lifeguards after simulated cardiac arrest due to drowning. Am J Emerg Med 2011;29(9):1044-50.

14. Barcala-Furelos R, Abelairas-Gomez C, Romo-Perez V, Palacios-Aguilar J. Effect of physical fatigue on the quality of cardiopulmonary resuscitation: a water rescue study of lifeguards. Am J Emerg Med 2013;31(3):473-7.

15. Perkins GD, Colquhoun M, Simons R. Training Manikins. In: Colquhoun M, Handley AJ, Evans TR, editors. ABC of Resuscitation. 5th ed. London: BMJ Publishing Group. 2004. p. 97-101

16. Perkins GD. In-water resuscitation: a pilot evaluation. Resuscitation 2005;65(3):321-4

17. Szpilman D, Soares M. In-water resuscitation--is it worthwhile? Resuscitation 2004;63(1):25-31. 
18. Szpilman D, Bierens JJLM, Handley AJ, Orlowski JP. Drowning. N Engl J Med 2012;366(22):2102-10.

19. Moran K, Webber J. Too Much Puff, Not Enough Push? Surf Lifeguard Simulated CPR. Int J Aquat Res Educ 2013;7(1):13-23.

20. Ashton A, McCluskey A, Gwinnutt CL, Keenan AM. Effect of rescuer fatigue on performance of continuous external chest compressions over 3 min. Resuscitation 2002;55(2):151-5.

21. Chi C-H, Tsou J-Y, Su F-C. Effects of compression-to-ventilation ratio on compression force and rescuer fatigue during cardiopulmonary resuscitation. Am J Emerg Med 2010;28(9):1016-23.

22. Hong CK, Park SO, Choi CS, Lee YH, Sung AJ, Lee JH, et al. Evaluation of chest compression depth during nine minutes of hands-only cardiopulmonary resuscitation performed by a lone rescuer and its effect by age group: A pilot simulation study using a manikin. Hong Kong J Emerg Med 2013;20(1):9-17.

23. Russo SG, Neumann P, Reinhardt S, Timmermann A, Niklas A, Quintel M, et al. Impact of physical fitness and biometric data on the quality of external chest compression: a randomised, crossover trial. BMC Emerg Med 2011;11:20.

24. Bjørshol CA, Søreide E, Torsteinbø TH, Lexow K, Nilsen OB, Sunde K. Quality of chest compressions during 10 min of single-rescuer basic life support with different compression: ventilation ratios in a manikin model. Resuscitation 2008;77(1):95-100.

25. Kim CH, Kim GW. The efficacy of alternative cardiopulmonary resuscitation methods when compared to standard cardiopulmonary resuscitation: A simulation study. Hong Kong J Emerg Med 2012;19(4):242-8.

26. Weisfeldt ML, Sitlani CM, Ornato JP, Rea T, Aufderheide TP, Davis D, et al. Survival after application of automatic external defibrillators before arrival of the emergency medical system: evaluation in the resuscitation outcomes consortium population of $21 \mathrm{million}$. J Am Coll Cardiol 2010;55(16):1713-20.

27. Halperin H, Carver DJ. Mechanical CPR devices. Signa Vitae 2010;5(Suppl. 1):69-73.

28. Putzer G, Braun P, Zimmermann A, Pedross F, Strapazzon G, Brugger H, et al. LUCAS compared to manual cardiopulmonary resuscitation is more effective during helicopter rescue-a prospective, randomized, cross-over manikin study. Am J Emerg Med 2012;31(2):384-9.

29. Winkler BE, Eff AM, Eff S, Ehrmann U, Koch A, Kähler W, et al. Efficacy of ventilation and ventilation adjuncts during in-water-resuscitation - A randomized cross-over trial. Resuscitation 2013;84(8):1137-42.

30. Adelborg K, Dalgas C, Grove EL, Jørgensen C, Al-Mashhadi RH, Løfgren B. Mouth-to-mouth ventilation is superior to mouth-to-pocket mask and bag-valve-mask ventilation during lifeguard CPR: A randomized study. Resuscitation 2011;82(5):618-22. 